\title{
3D-printed Holistic Reactors with Fractal Structure for Heterogeneous Reaction
}

\author{
Xueyan Sun ${ }^{1}$, Zhigang Wang ${ }^{2}$, Chong Li $^{1}$, Lijing Zhang ${ }^{1}$, Wenbo Yang ${ }^{1}$, and Shengyang \\ $\mathrm{TaO}^{1}$ \\ ${ }^{1}$ Dalian University of Technology \\ ${ }^{2}$ National University of Singapore
}

July 7, 2020

\begin{abstract}
Holistic catalytic reactors with fractal structure have attracted growing attention in heterogeneous reactions because of its advantages of improved mass transfer and easy separation. Herein, a simple and cost-efficient design strategy that combined 3D printing and electroless deposition was presented to construct dynamic, holistic stirred reactors with the fractal structure. The conversion factor $\alpha$ of fractal impeller is $65.01 \mathrm{mmol} \mathrm{m-2} \mathrm{h-1} \mathrm{with} \mathrm{a} \mathrm{large} \mathrm{volume} \mathrm{of} \mathrm{reactant} \mathrm{(} 80 \mathrm{~mL})$, which is 1.7 times that of the normal impeller with the same Ag catalysts. Experimental results and simulation analysis demonstrate that the fractal impeller significantly improves the catalytic performance by enhancing mass transfer and spatial dispersion in the reaction. Moreover, the holistic impeller could be reused for ten times without obvious loss of catalytic performance, and easily separated from the reaction system. The structural design of fractal reactors will open the way for a new efficient dynamic heterogeneous catalytic reactor.
\end{abstract}

\section{Hosted file}

manuscript.docx available at https://authorea.com/users/340708/articles/467769-3d-printedholistic-reactors-with-fractal-structure-for-heterogeneous-reaction 